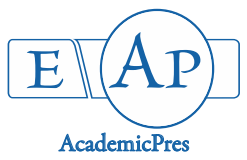

Imade OS et al. (2020)

Notulae Scientia Biologicae 12(1):172-183

DOI: $10.15835 / \mathrm{nsb} 12110633$

Research Article

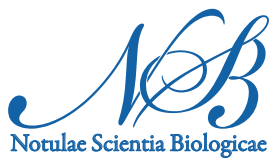

\title{
The risk mitigation indices associated with some risk mitigation protocols performed on contaminated aqua-cultured catfish (Clarias gariepinus)
}

\author{
Odaro S. IMADE ${ }^{1 *}$, Faith I. AKINNIBOSUN² \\ ${ }^{1}$ Igbinedion University, College of Natural and Applied Sciences, Department of Biological Sciences, Okada, Edo State, \\ Nigeria; imade.stanley@gmail.com (*correspondingauthor) \\ ${ }^{2}$ University of Benin, Faculty of Life Sciences, Department of Microbiology, Benin City, Edo State, Nigeria; fakinnibosun@yahoo.co.uk
}

\begin{abstract}
The present research quantified the risk mitigation indices associated with some risk mitigation protocols practiced by humans in Nigeria to mitigate the baseline risk of illness that were associated with Clarias gariepinus contaminated with multidrug-resistant AmpC beta-lactamase-producing Enterobacter cloacae pathogen. Identification of the multidrug-resistant AmpC beta-lactamase-producing E. cloacae pathogen was performed with phenotypic and molecular methods. The United States FDA-iRisk stochastic software quantified the baseline and residual risk of illness associated with the contamination and crosscontamination routes of the $C$. gariepinus chain. The fresh adult $C$. gariepinus was contaminated with the multidrug-resistant $E$. cloacae pathogen (median concentration $=4.49 \mathrm{CFU} \mathrm{g}^{-1}$ ), but this was significantly reduced by the risk mitigation protocols practiced by the human consumers. The risk mitigation practices of human consumers resulted in a risk mitigation index of 0.92 , which was equivalent to a $92 \%$ reduction in the baseline risk of illness (baseline risk of illness $=7.58 \times 10^{-4}$; residual risk of illness $=5.9 \times 10^{-5}$ ). In spite of the significant risk mitigation, inducible AmpC beta-lactamase resistance genes was still found in the residual multidrug-resistant Enterobacter cloacae pathogen, which survived the inadequate risk mitigation protocols that accounted for $8 \%$ residual risk of illness.
\end{abstract}

Keywords: bio-risk; cross-contamination; multidrug-resistant AmpC beta-lactamase-producing Enterobactercloacae pathogen

\section{Introduction}

The absence of control of catfish aquaculture operations in Nigeria and many developing countries (Boss et al., 2016) could have a profound negative health impact on humans, especially as a result of probable improper handling of the contaminated catfish during processing in kitchen systems (Barker et al., 2003).

An array of pathogenic bacteria, parasites and viruses (Pires et al., 2015) has been implicated as the main sources of contamination in aquaculture systems. The health impact resulting from these contaminations and cross-contaminations is often deduced by estimating the risk or probability of illness 
caused by the contaminated food (Cassini et al., 2016). The baseline risk of illness is defined as a measure of the health impact that is associated with the contaminated food that had not been subjected to any form of risk mitigations such as thermal processing or chemical disinfection. The residual risk of illness refers to a measure of the health impact that remained in the contaminated food after the implementation of some forms of risk mitigation protocols during processing of the contaminated foods in kitchen systems.

Evaluations of the baseline and residual risk of illness in the catfish aquaculture chain usually involve the use of quantitative tools (FDA/CFSAN/JIFSAN/RSI, 2017) that can predict the risks of illnesses resulting from catfish contaminations and cross-contamination. The Codex Committee on Food Hygiene Principles and Guidelines for the Conduct of Microbiological Risk Assessment (Codex Alimentarius Commission, 1999), which consists of a hazard identification, hazard characterization, exposure assessment, and risk characterization (Park et al., 2014) is a routine risk assessment tool that is widely used for these microbial risk predictions.

It has been asserted that Africa has the greatest burden of disease from contaminated foods among all age groups (Kirk et al., 2017). Hence, the hereby research aimed to specifically quantify the baseline risk of illness that was associated with fresh C. gariepinus harvested from Nigerian grow-out pond systems, as well as to assess the efficacy of the confounding risk mitigation protocols in the Nigerian C. gariepinus chain, as measured by the residual risk of illness.

\section{Materials and Methods}

Experimental design

Fifty-four fresh adult C. gariepinus samples were collected from the grow-out pond systems in Nigeria. The C. gariepinus samples were individually analyzed to estimate the extent of contamination of the catfish samples with multidrug-resistant Enterobacter cloacae pathogen. C. gariepinus samples were also used to estimate the extent of cross-contamination in ready-to-eat salad samples that were cross-contaminated by contaminated catfish contact surfaces (knife, cutting tray, and processor's hands) after some forms of risk mitigation protocols were initially applied to decontaminate the catfish contact surfaces which were previously used to process the catfish samples. Exposure variables (concentration and prevalence) were measured in the contaminated catfish and cross-contaminated ready-to-eat salad samples.

\section{Preparation of catfish and ready-to-eat salad for microbial analyses}

Each adult C. gariepinus sample was dissected on a metal tray that had been initially sterilized in a hot air oven. It was then dissected with a sterilized surgical blade and some portion of the skin, alimentary organs, and gills were aseptically removed for analysis.

Having removed the materials to be analyzed from a C. gariepinus sample, a sterile knife was subsequently used to partition the C. gariepinus in the laboratory, as is practiced in the kitchen by human consumers in Nigeria. The knives, cutting tray and processors' hands were then decontaminated in the laboratory via three risk mitigation scenarios, as is also practiced by human consumers in Nigeria. The risk mitigation scenarios performed in the laboratory included:

i. rinsing of the catfish contact surfaces with sterile water only.

ii. aseptic scrubbing of the catfish contact surfaces with soap plus rinsing with sterile water.

iii. aseptic scrubbing of the catfish contact surfaces with soap plus rinsing with sterile water containing 5,000 ppm hypochlorite.

After each risk mitigation scenario, the decontaminated catfish contact surfaces were then used to slice salad ingredients (carrot, garbage and cucumber) that had initially been sterilized to eliminate extraneous pathogens. The sliced ingredients were then incorporated into the mayonnaise cream to produce the 
174

prototype ready-to-eat salad sample that was analyzed to indirectly estimate the efficacy of the risk mitigation protocols that were used to mitigate the health impact of the catfish cross-contamination routes.

A fourth risk mitigation scenario was also performed in the laboratory, to estimate the efficacy of mitigating the baseline risk of illness caused by the contaminated catfish. It involved cooking of the partitioned C. gariepinus to an internal temperature of $68^{\circ} \mathrm{C}$ (internal temperature of well-cooked catfish) according to the method of Jackson et al. (1996), as also practiced by human consumers in Nigeria.

Estimation of the initial prevalence and concentration of multidrug-resistant AmpC beta-lactamaseproducing E. cloacae pathogen

Spread-plating technique was used to screen the samples for the presence of drug-resistant enteric bacterial colonies by inoculating samples on to ceftriaxone-impregnated crystal violet red bile (CVRB) agar plates (CLSI, 2014; Imade and Akinnibosun, 2018). The plates were incubated at $37^{\circ} \mathrm{C}$ for $18-24$ hours and the concentration of ceftriaxone-resistant enteric bacteria was subsequently deduced and reported as ceftriaxone-resistant enteric bacteria counts (CREC).

Detection of multidrug resistance in the ceftriaxone-resistant colonies was performed with the Kirby Bauer disk diffusion test (CLSI, 2014). Ceftriaxone-resistant bacterial colonies that exhibited resistance to at least two antibiotics from two different antibiotics classes used in the disk diffusion test were confirmed as multidrug-resistant bacteria.

Genus-level identification of multidrug-resistant $E$. cloacae pathogen was performed with standard phenotypic testing of the multidrug-resistant bacteria (Barrow and Feltham, 2013).

Haemocytotoxigenic and Shigatoxigenic virulence traits in the multidrug-resistant bacteria were also detected as previously described (Karch and Meyer, 1989; Surendran and Thampuran, 2009; Imade and Akinnibosun, 2018).

Species-level identification of the multidrug-resistant AmpC beta-lactamase-producing E. cloacae pathogen was performed with molecular methods (Lane, 1991; Conceicao et al., 2004; Imade and Akinnibosun, 2018).

The concentration of the multidrug-resistant AmpC beta-lactamase-producing E. cloacae pathogen in a catfish sample was deduced with equations 1 and 2. Prevalence of contaminated catfish sample(s) in the batch of catfish samples examined in this study was calculated with equation 3 .$$
C_{a m}\left(C F U g^{1}\right)=P_{a m} \times C R E C
$$

$\mathrm{C}_{\text {am }}$ : concentration of multidrug-resistant AmpC beta-lactamase-producing E. cloacae pathogen in a catfish sample. CREC: concentration of ceftriaxone-resistant enteric bacteria in a catfish sample. $P_{a m}$ : prevalence of multidrug-resistant AmpC beta-lactamase-producing E. cloacae pathogen in a catfish sample, mathematically expressed as follows:

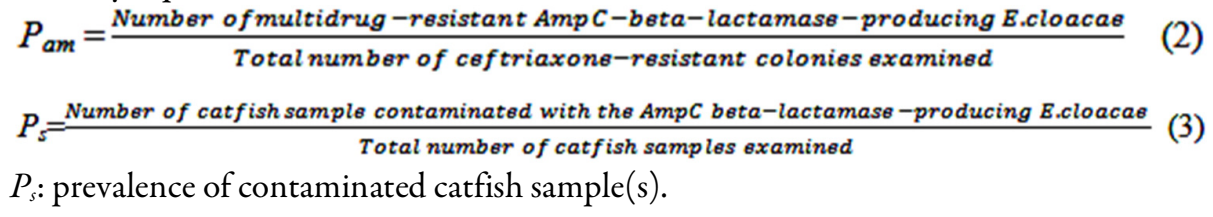

$P_{s}:$ prevalence of contaminated catfish sample(s).

\section{Stochastic quantification of the baseline risk of illness associated with the contaminated fresh catfish}

The baseline risk of illness inferred the degree of health risk that humans were exposed to if appropriate intervention protocols were not performed prior to consumption of the fresh C. gariepinus harvested from the grow-out ponds. The baseline risk of a case of illness per serving was calculated across all the iterations simulated with the FDA-iRisk software as follows:

$$
P_{f, h}=E\left[P\left(\varepsilon_{h} / A D_{f, h}\right) \times P\left(\gamma_{h} / \varepsilon_{h}\right) \times P_{s}\right]
$$


$P_{f, b}$ : probability (baseline risk) of a case of illness. $P\left(\varepsilon_{b} / A D_{f, b}\right)$ : probability of response provided by interpolation from the dose-response model specified for hazard $h$, given ingestion of dose $A D_{f, b} . P\left(\gamma_{b} / \varepsilon_{b}\right)$ : probability of acute illness given response $\varepsilon_{b}$ occurred if $\varepsilon_{b}$ is an end point other than frank illness. $P_{s}$ (probability of exposure): prevalence of contaminated units of catfish provided by the process model. $E$ denotes the expectation of the value in the brackets, as computed from the mean of the iterations within a Monte Carlo simulation.

Quantitative modelling of risk mitigation protocols

Modelling of the decontamination (risk mitigation) protocols employed in kitchen systems during partitioning of contaminated aqua-cultured C. gariepinus was based on the behavioural practices of human consumers during processing of the catfish in kitchen systems. A descriptive study was employed, in which a sample size of 1,050 respondents drawn from Edo (Latitude: $6.5438^{\circ} \mathrm{N}, 5.8987^{\circ} \mathrm{E}$ ), Anambra (Latitude: $6.8959^{\circ} \mathrm{N}, 4.8936^{\circ} \mathrm{E}$ ) and Ondo (Latitude: $6.2758^{\circ} \mathrm{N}, 7.0068^{\circ} \mathrm{E}$ ) States in Nigeria were enrolled and a structured self-reported questionnaire administered to each of the respondents. The responses were subsequently analyzed with the NCSS version 12 Data Analysis software.

\section{Process model description of C. gariepinus contamination/cross-contamination}

Three processing stages were formulated to depict the $C$. gariepinus contamination route in the $C$. gariepinus chain. These stages include the hatchery/pre-harvest, harvest and partitioning stages. The three stages spanned the time the fresh fingerlings/juveniles (which were harvested from the nursery pond at the end of the hatchery/pre-harvest stage) entered the grow-out pond to the time they reached adult size in the grow-out pond (at the end of the harvest stage) and ultimately to the time the adult C. gariepinus were processed in the kitchen (partitioning stage).

The C. gariepinus cross-contamination route was depicted with two processing stages. One of the stages comprise the cross-contamination of food contact surfaces, such as kitchen utensils and the hands of the processors, during the partitioning of catfish in the kitchen; the other processing stage depicts a scenario in which ready-to-eat salad was cross-contaminated with improperly decontaminated food contact surfaces prior to consumption.

\section{Calculation of the residual risk of illness resulting from the risk mitigation protocols}

The health impact of the risk mitigation protocols practiced by human consumers in Nigeria during catfish processing in the kitchen was deduced as follows:

$$
R_{i}=1-\frac{\boldsymbol{R} \boldsymbol{c}}{\boldsymbol{R} \boldsymbol{b}}
$$

$R_{i}$ is the risk mitigation index.

$R b$ is the baseline risk of a case of illness caused by the contaminated fresh catfish.

$R c$ is the residual risk of a case of illness across all the risk mitigation protocols examined. It is mathematically represented as:

$$
R c=\frac{\sum(F p \times R p)}{N}
$$

$F p$ : frequency of a specific risk mitigation protocol practiced by human consumers. $R p$ : residual risk of a case of illness resulting from a specific risk mitigation protocol. $N$ : total number of risk mitigation protocol(s) examined.

Data analysis

NCSS version 12 data analysis software was used to analyse the descriptive statistics of concentration and prevalence data. The NCSS version 12 data analysis software was also used to implement the Wei's Urn 
176

iterative randomization protocol, Shapiro Wilk normality test, Levene test of homogeneity and KruskalWallis non-parametric ANOVA test. The FDA-iRisk stochastic software estimated the baseline and residual risk of illness that was associated with the C. gariepinus chain.

\section{Results}

Identification of multidrug-resistant AmpC beta-lactamse-producing E. cloacae pathogen

GenBank accession numbers for deposited strains of the isolated multidrug-resistant E. cloacae pathogen were MH071286 and MH027596. Metadata which described these isolated strains as pathogens affecting public health were also deposited under GenBank accession numbers SAMN08728319 and SAMN0878310. The annotated AmpC $\beta$-lactamase enzymes as well their translated nucleotide sources were deposited under GenBank accession numbers AXH01353, AXH01354, MH110562 and MH110563. GenBank accession numbers for metadata which described these isolated multidrug-resistant pathogenic strains as AmpC $\beta$-lactamase producers were SAMN08728284 and SAMN08728333. A pair-wise amino acid sequence alignment between the AmpC $\beta$-lactamase (AXH01353) produced by a pathogenic multidrugresistant isolate (Enterobacter cloacae NG 14) and the consensus sequence of its cubic O group peptidase family, which further confirmed the production of AmpC beta-lactamase by the isolated E. cloacae pathogen is shown in Figure 1.

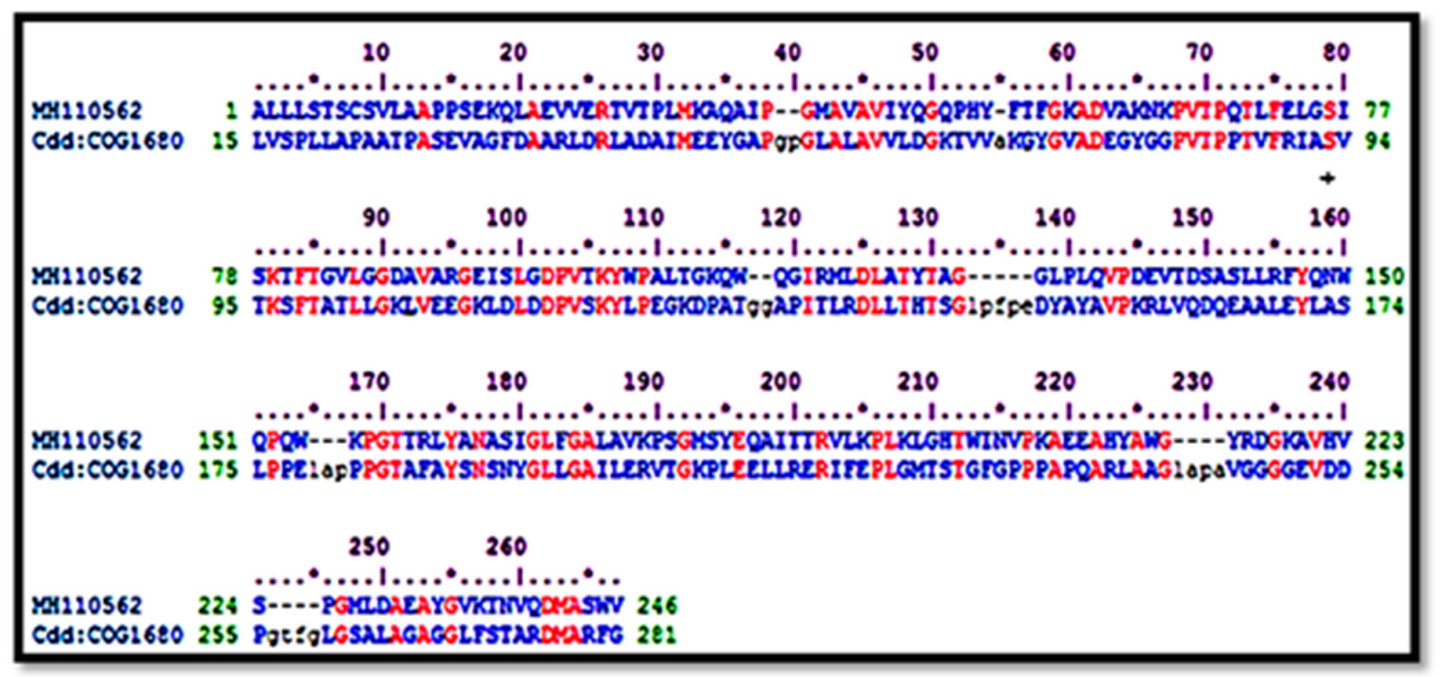

Figure 1. RPS-BLAST pair-wise sequence alignments between the AmpC beta-lactamase amino acid residues of cubic $\mathrm{O}$ group peptidase consensus sequence (COG1680) and the query AmpC betalactamase amino acid residues (AXH01353) derived from the translated nucleotide sequence (MH110562) of E. cloacae HK 14. COG1680 is the accession number of the specific hit (cubic O group peptidase conserved domain database. $(+)$ symbol indicate the specific location of the serine active site within the highly conserved motifs. (- - -) indicate regions of amino acid sequence deletions in the AmpC beta-lactamase enzyme due to mutations in the query translated nucleotide sequence. The BLAST was implemented with the conserved domain bioinformatics tool (CD SEARCH/cdd v3.16) 
FDA-iRisk inputs used for the stochastic quantification of aquaculture operations (putative risk factors) in the grow-out pond systems

Descriptive statistical variables of the initial concentration and prevalence of multidrug-resistant AmpC beta-lactamase-producing E. cloacae pathogen present in the fresh C. gariepinus samples that were inputted as probability distributions into the FDA-iRisk software to stochastically quantify the variability in the concentration of the pathogen are presented in Table 1. Quantification of the variability in concentration parameter was based on the outcome of the normality test performed on the initial concentration datasets of the pathogen. Concentration datasets of the pathogen in the fresh $C$. gariepinus were non-normally distributed ( $\mathrm{p}<0.05$ ). Thus, triangular probability distribution [expressed as Triangular (Minimum, Mode, Maximum)] was used to stochastically quantify the concentration of the pathogen in the fresh C. gariepinus samples.

Table 1. Variables inputted into FDA-iRisk software for stochastic quantification of variability in the concentration of the pathogen in C. gariepinus

\begin{tabular}{|c|c|c|c|c|}
\hline \multirow{4}{*}{ Predictor pathogen } & \multirow{2}{*}{ Parameters } & $\begin{array}{c}|c| \\
\text { Prevalence of } \\
\text { contaminated } \\
\text { catfish }\end{array}$ & $\begin{array}{c}\text { Amount of } \\
\text { contamination } \\
\text { added }\end{array}$ & $\begin{array}{c}\text { Concentration } \\
\text { after addition } \\
\text { process }\end{array}$ \\
\cline { 3 - 5 } & & $(A)\left(\log _{10}\right.$ CFU $)$ & $\left(C_{i}\right)\left(\log _{10}\right.$ CFU g-1 $)$ \\
\hline \multirow{5}{*}{ Enterobacter cloacae } & Mean & 0.84 & 5.18 & 4.04 \\
\cline { 2 - 5 } & Median & 1.00 & 5.88 & 4.79 \\
\cline { 2 - 5 } & Mode & 1.00 & 6.58 & 5.18 \\
\cline { 2 - 5 } & Standard deviation & 0.24 & 1.71 & 1.42 \\
\cline { 2 - 5 } & Minimum & 0.00 & 0.00 & 0.00 \\
\cline { 2 - 5 } & Maximum & 1.00 & 7.49 & 6.10 \\
\hline
\end{tabular}

$\mathrm{N}$ represents the total number of catfish samples examined.

\section{FDA-iRisk inputs used for the stochastic quantification of confounding risk factors in the kitchen system}

Process modelling of the confounding risk factors was based on the risk mitigation behaviours of human consumers in Nigeria during catfish processing in the kitchen as indicated in Table 2. All respondents said that they ensured that catfish was well-cooked prior to consumption. Thus, upon modelling of the risk mitigation scenario in which fresh catfish samples were cooked to an internal temperature of $68^{\circ} \mathrm{C}$ (internal temperature of well-cooked catfish) according to the method of Jackson et al. (1996), the E. cloacae pathogen was not found in all the well-cooked catfish samples examined. Nine per cent of respondents rinsed catfish contact surfaces (knife, cutting board and processors' hands) with water only after the use of these contact surfaces to process catfish in the kitchen. Upon modelling of this risk mitigation scenario in the laboratory, the $E$. cloacae pathogen was found in the cross-contaminated ready-to-eat salad samples. The pathogen was also found in another risk mitigation scenario in which ready-to-eat salad samples were cross-contaminated by pre-sterilized salad ingredients (carrot, cucumber, garbage) that were sliced with catfish contact surfaces that had initially been scrubbed with soap and rinsed in sterile water after their use to partition fresh $C$. gariepinus samples in the laboratory. No E. cloacae pathogen was isolated from ready-to-eat salad samples in the risk mitigation scenario in which the ready-to-eat salad samples were prepared with pre-sterilized salad ingredients that were sliced with catfish contact surfaces which had initially been scrubbed with soap and rinsed in sterile water containing 5,000 ppm hypochlorite after their use to partition fresh catfish samples in the laboratory.

Descriptive statistical variables of the initial concentration and prevalence of the $E$. cloacae pathogen harbored in the cross-contaminated ready-to-eat salad samples that were inputted as probability distributions into the FDA-iRisk software to stochastically quantify the variability in the concentration parameter are 
178

presented in Table 3. The resultant probability distributions of the initial concentration datasets which was used by the FDA-iRisk software to implement the Latin Hypercube sampling that generated multiple datasets (iterations) used in performing Monte Carlo simulations of the risk mitigation events in the kitchen systems is shown in Figure 2.

Table 2. Risk mitigation behaviors of human consumers during C. gariepinus processing in kitchen systems

\begin{tabular}{|c|c|c|c|c|}
\hline \multirow{7}{*}{1.} & \multirow{2}{*}{ Question types } & \multicolumn{3}{|c|}{$\begin{array}{l}\text { Subjects' response to questions } \\
\qquad(\mathrm{N}=1050)\end{array}$} \\
\hline & & $\begin{array}{c}\text { Mean } \\
(\times 100 \%)\end{array}$ & $\begin{array}{l}\text { S. error } \\
(\times 100 \%)\end{array}$ & $\begin{array}{l}95 \% \mathrm{CI} \\
(\times 100 \%) \\
\end{array}$ \\
\hline & \multicolumn{4}{|c|}{$\begin{array}{l}\text { Sanitization of hands, knife and cutting board } \\
\text { after their use to process catfish in the kitchen: }\end{array}$} \\
\hline & i. rinse with water only & 0.09 & 0.01 & $0.07-0.11$ \\
\hline & ii. scrub with soap followed by rinsing with water & 0.89 & 0.01 & $0.87-0.91$ \\
\hline & iii. scrub with soap followed by rinsing with water & 0.02 & 0.00 & $0.01-0.03$ \\
\hline & containing 5,000 PPM hypochlorite. & & & \\
\hline \multirow{3}{*}{2.} & \multicolumn{4}{|c|}{ Cooking of catfish prior to consumption: } \\
\hline & i. well-cooked before consumption & 1.00 & 0.00 & $0.00-0.00$ \\
\hline & ii. consumed even when not properly cooked & 0.00 & 0.00 & $0.00-0.00$ \\
\hline
\end{tabular}

$\mathrm{N}$ : total number of human respondents. PPM: parts per million. S. Standard. CI: confidence interval of mean

Table 3. Variables inputted into FDA-iRisk software for stochastic quantification of variability in the concentration of the pathogen in cross-contaminated ready-to-eat salad

\begin{tabular}{|c|c|c|c|c|c|c|c|c|c|}
\hline \multirow{4}{*}{$\begin{array}{c}\text { Specific } \\
\text { hazard }\end{array}$} & \multirow{4}{*}{$\begin{array}{c}\text { Statistical } \\
\text { parameters }\end{array}$} & \multicolumn{8}{|c|}{ Risk mitigation protocols in kitchen systems } \\
\hline & & \multirow{2}{*}{\multicolumn{4}{|c|}{$\begin{array}{l}\text { Cross-contamination of ready-to-eat salad samples with } \\
\text { catfish contact surfaces which were rinsed with water } \\
\text { only } \\
(\mathrm{N}=18)\end{array}$}} & \multirow{2}{*}{\multicolumn{4}{|c|}{$\begin{array}{l}\text { Cross-contamination of ready-to-eat salad samples with } \\
\text { catfish contact surfaces which were scrubbed with soap } \\
\text { and rinsed with water } \\
(\mathrm{N}=18)\end{array}$}} \\
\hline & & & & & & & & & \\
\hline & & $\begin{array}{c}\text { Prevalence } \\
\text { of ready } \\
\text { to-eat } \\
\text { salad }\end{array}$ & $\begin{array}{c}\text { Amount of } \\
\text { contamination } \\
\text { added }(A) \\
\left(\log _{10} \mathrm{CFU}\right)\end{array}$ & $\begin{array}{l}\text { Transfer } \\
\text { rate }(T) \\
(\times 100 \%)\end{array}$ & $\begin{array}{l}\text { Concentration } \\
\text { after addition } \\
\text { process }\left(C_{i}\right) \\
\left(\log _{10} \quad \mathrm{CFU}\right. \\
\left.\mathrm{g}^{1}\right)\end{array}$ & $\begin{array}{c}\text { Prevalence } \\
\text { of ready } \\
\text { to-eat } \\
\text { salad }\end{array}$ & $\begin{array}{l}\text { Amount of } \\
\text { contaminati } \\
\text { on } \\
\text { added }(A) \\
\left(\log _{10} \mathrm{CFU}\right)\end{array}$ & $\begin{array}{l}\text { Transfer } \\
\text { rate }(T) \\
(\times 100 \%)\end{array}$ & $\begin{array}{c}\text { Concentration } \\
\text { after addition } \\
\text { process }\left(C_{i}\right) \\
\left(\log _{10} \mathrm{CFU} \mathrm{g} \mathrm{g}^{1}\right)\end{array}$ \\
\hline \multirow{7}{*}{$\begin{array}{c}\text { Enterobacter } \\
\text { cloacae }\end{array}$} & Mean & 1.00 & 4.11 & 0.92 & 2.71 & 0.22 & 0.80 & 0.19 & 0.49 \\
\hline & Median & 1.00 & 4.10 & 0.94 & 2.70 & 0.00 & 0.00 & 0.00 & 0.00 \\
\hline & Mode & 1.00 & 4.10 & 0.94 & 2.70 & 0.00 & 0.00 & 0.00 & 0.00 \\
\hline & Std. Dev. & 0.00 & 0.14 & 0.04 & 0.14 & 0.43 & 1.55 & 0.37 & 0.95 \\
\hline & Minimum & 1.00 & 3.80 & 0.83 & 2.40 & 0.00 & 0.00 & 0.00 & 0.00 \\
\hline & Maximum & 1.00 & 4.33 & 0.97 & 2.93 & 1.00 & 3.80 & 0.91 & 2.40 \\
\hline & $95 \% \mathrm{CI}$ & $1.00-1.00$ & $4.04-4.18$ & $0.91-0.95$ & $2.64-2.78$ & $0.01-0.44$ & $0.03-1.57$ & $0.01-0.37$ & $0.02-0.97$ \\
\hline
\end{tabular}

$\mathrm{N}$ : number of samples examined. CI: confidence interval of mean.

In the risk mitigation scenario in which catfish contact surfaces were rinsed with water only prior to their use to slice the salad ingredients, the concentration datasets of the multidrug-resistant $E$. cloacae pathogen present in the cross-contaminated ready-to-eat salad samples were normally distributed $(\mathrm{p}>0.05)$. Hence, for this scenario, normal-truncated probability distribution [expressed as Normal-Truncated (Mean, Standard deviation, Lower bound, Upper bound)] was used to stochastically quantify the concentration of the E. cloacae pathogen in the cross-contaminated ready-to-eat salad samples. However, in the risk mitigation scenario in which catfish contact surfaces were aseptically scrubbed with soap and then rinsed with sterile water prior to their use to slice the pre-sterilized salad ingredients, the concentration datasets of the E. cloacae pathogen present in the cross-contaminated ready-to-eat salad samples was non-normally distributed ( $\mathrm{p}<$ 0.05). Thus, for this scenario, triangular probability distribution [expressed as Triangular (Minimum, Mode, 
Maximum)] was used to stochastically quantify the variability in the concentration of the pathogen in the cross-contaminated ready-to-eat salad samples.

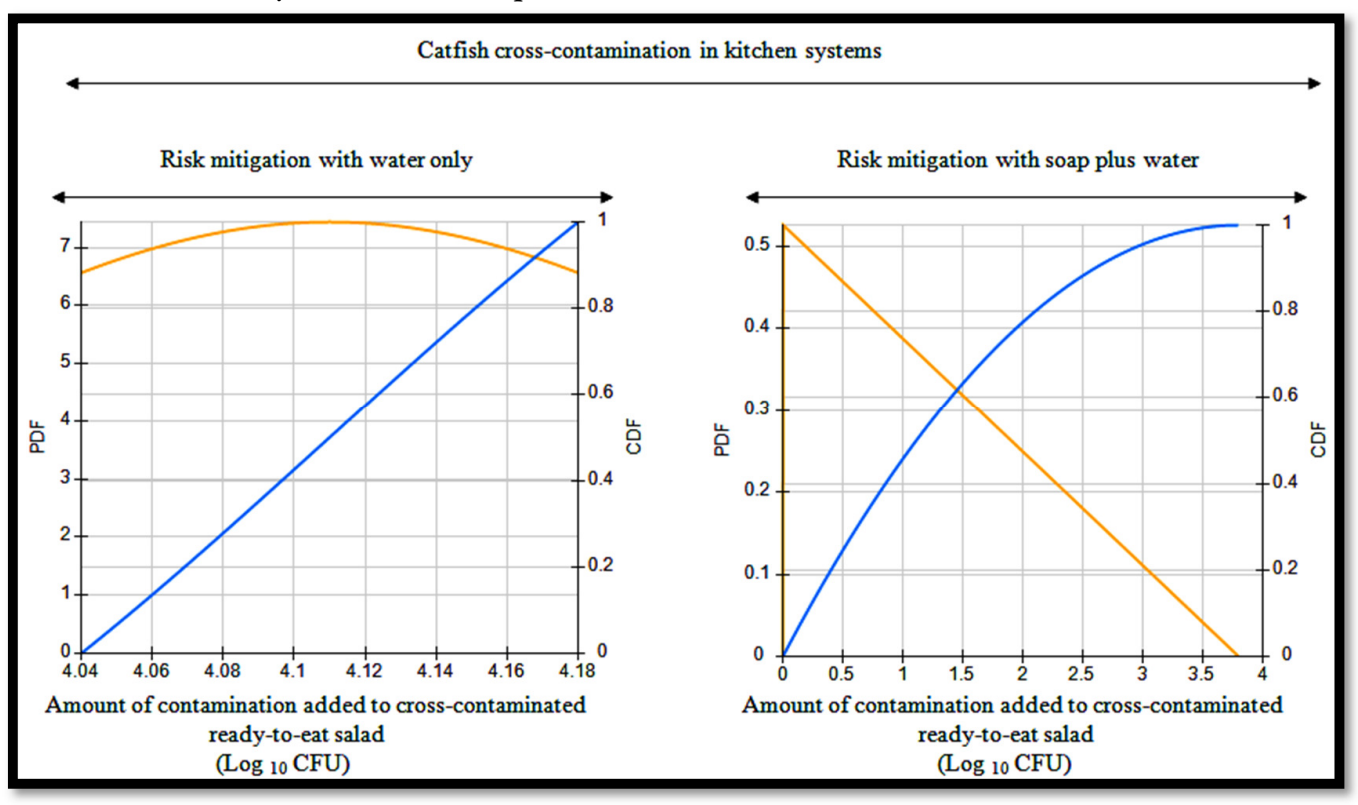

Figure 2. Probability distribution curves used in implementing the Monte-Carlo simulations used for the stochastic quantification of the variability in the concentration of multidrug-resistant AmpC betalactamase-producing Enterobacter cloacae pathogen in the cross-contaminated ready-to-eat salad. PDF (yellow line) represents probability density function. CDF (blue line) represents the cumulative distribution function. It was implemented with the FDA-iRisk version 4.0 software

\section{Other modelling parameters inputted into the FDA-iRisk software}

Serving size inputted into the FDA-iRisk software was stipulated by the United States Food and Drug Association (FDA) and Environmental Protection Agency (EPA) (FDA and EPA, 2017). The population group that was examined was the immune-compromised HIV/AIDS adult population group and the inputted serving sizes of fresh C. gariepinus and ready-to-eat salad for this population group was estimated at values of $113.4 \mathrm{~g}$ and $113.4 \mathrm{~g}$ respectively. Thus, the inputted dose was equivalent to the product of the serving size and concentration of the multidrug-resistant AmpC beta-lactamase-producing E. cloacae pathogen present in the C. gariepinus and/or ready-to-eat salad samples which was derived from the process modelling of the catfish grow-out ponds and/or kitchen systems.

The dose-response curve for the pathogen is shown in Figure 3. The infectious dose of E. cloacae $(1 \times$ $10^{3} \mathrm{CFU}$ ) stipulated by the Canadian Pathogen Regulation Directorate (2010) was inputted into the FDAiRisk software as an r-parameter (the probability that a single pathogen survived and initiated an illness, which was estimated at 0.001 ).

\section{FDA-iRisk output of the baseline risk of illness}

In the absence of adequate microbial mitigation protocols during the processing of fresh C. gariepinus by human consumers, the presence of multidrug-resistant AmpC beta-lacatamase-producing E. cloacae pathogen in the fresh catfish appeared to pose significant risk of illness to potential immune-compromised consumers, since 758 potential immune-compromised consumers were most likely to fall ill per one million potential immune-compromised consumers that were exposed to the contaminated catfish. 


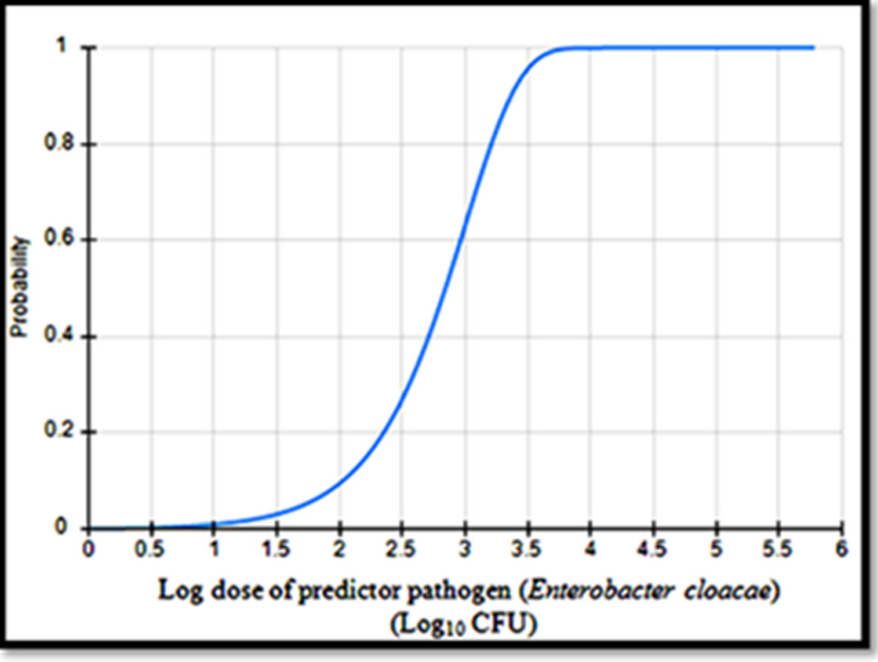

Figure 3. Dose-response curve of the Enterobacter cloacae pathogen. The dose-response curve was implemented with the FDA-iRisk version 4.0 software

\section{FDA-iRisk output of the residual risk of illness}

Due to the improper risk mitigation protocols still practiced by some human consumers during processing of fresh C. gariepinus in kitchen systems, residual risks were associated with some of the risk mitigation scenarios modelled in the laboratory as represented in Table 4. Upon risk mitigation with sterile water only, as well as with soap plus rinse with sterile water, residual risks of a case of illness were estimated at $9.74 \times 10^{-4}$ and $9.92 \times 10^{-5}$ respectively. However, no residual risk of illness was associated with the remaining two risk mitigation scenarios in which catfish contact surfaces were initially scrubbed with soap and then rinsed with sterile water containing $5,000 \mathrm{ppm}$ hypochlorite, as well as the scenario in which fresh $C$. gariepinus were well-cooked prior to consumption.

Table 4. Quantitative outputs of the residual risk of illness

\begin{tabular}{|c|c|c|c|c|c|c|c|c|c|c|c|}
\hline \multicolumn{12}{|c|}{ Parameters } \\
\hline \multicolumn{4}{|c|}{$R p$} & \multicolumn{4}{|c|}{$F p \times R p$} & $R c$ & $R b$ & \multicolumn{2}{|c|}{$R_{i}$} \\
\hline W & WS & WSH & TT & $\mathrm{W}$ & WS & WSH & TT & \multirow{2}{*}{\multicolumn{2}{|c|}{$\left(\times 10^{-4}\right)$}} & $R_{i} c$ & $R_{i} c c$ \\
\hline \multicolumn{4}{|c|}{$\left(\times 10^{-4}\right)$} & \multicolumn{4}{|c|}{$\left(\times 10^{-4}\right)$} & & & & \\
\hline 9.74 & 0.99 & 0.00 & 0.00 & 0.88 & 0.88 & 0.00 & 0.00 & 0.59 & 7.58 & 1.00 & 0.92 \\
\hline
\end{tabular}

W: rinse with sterile water only; WS: scrub with soap plus rinse with sterile water; WSH: scrub with soap plus rinse with sterile water containing $5000 \mathrm{ppm}$ hypochlorite; TT: well-cooked $C$. gariepinus samples; $R p$ is the residual risk of a case of illness resulting from a specific risk mitigation protocol; $F p$ : the frequency of a specific risk mitigation protocol practised by the human population; $R c$ : residual risk of a case of illness across all the risk mitigation protocols of the cross-contamination route; $R b$ : baseline risk of a case of illness caused by the contaminated $C$. gariepinus harvested from the grow-out ponds; $R_{i}$ : risk mitigation index; $R_{i} c$ :risk mitigation index from the $C$. gariepinus contamination route: $R_{i} c c$ : risk mitigation indices from the $C$. gariepinus cross-contamination routes.

\section{Discussion}

The hereby research revealed that fresh C. gariepinus harvested from the grow-out ponds harboured high concentrations of multidrug-resistant AmpC beta-lactamase-producing E. cloacae pathogen (Table 2 and Figure 1). This agreed to earlier findings by Efuntoye et al. (2012), Adedeji and Onwenefah (2013) and 
Ekundayo et al. (2014) who indicated that there was an abundance of multidrug-resistant bacteria in the Nigerian catfish pond systems. However, in contrast to the present findings, Boss et al. (2016) who worked with aquaculture-produce from the European countries reported that no multidrug-resistant bacteria were found in aquaculture-produce collected from European aquaculture systems.

The baseline and residual risks of illness which was associated with C. gariepinus contamination and cross-contaminations were quantified with the FDA-iRisk version 4.0 stochastic software using inputs that were obtained from surveillance studies (Table 1), as well as inputs from experts' elicitations (FDA and EPA, 2017; Canadian Pathogen Regulation Directorate, 2010) (Figure 3) and human behavioural studies (Table 2).

As indicated in the present study, the multidrug-resistant AmpC beta-lactamase-producing E. cloacae pathogen in fresh C. gariepinus (Table 1 and Figure 2) was found at a relatively high concentration (median concentration $\left.=4.49 \log _{10} \mathrm{CFU} \mathrm{g} g^{-1}\right)$ that was significantly above standard bacteriological limit $\left(<2 \log _{10} \mathrm{CFU}\right.$ $\left.\mathrm{g}^{-1}\right)$, thus, implying a probable significant health consequence in humans, especially immune-compromised humans. This probable significant health consequence of the pathogen was further corroborated by a predicted baseline risk of $7.58 \times 10^{-4}$ in the immune-compromised population group examined in the study. However, this potentially huge burden resulting from the presence of the opportunistic $E$. cloacae pathogen in the Nigerian catfish grow-out ponds was significantly ameliorated by the risk mitigation protocols (Tables 3 and 4) practiced by human consumers in Nigeria. The risk mitigation practices of human consumers resulted in a risk mitigation index of 0.92 (Table 4), which was equivalent to a $92 \%$ reduction in the baseline line risk of illness (baseline risk of illness $=7.58 \times 10^{-4}$; residual risk of illness $=5.9 \times 10^{-5}$ ). Nevertheless, inducible AmpC beta-lactamase resistance genes were found in the residual multidrug-resistant E. cloacae pathogen present in the cross-contaminated ready-to-eat salad due to improper decontamination of the catfish contact surfaces. Because this resistance genes, which originates from the contaminated catfish, can be readily horizontally transferred (Pérez-Pérezand Hanson, 2002) to other clinically relevant pathogens present in other ready-to-eat foods, the C. gariepinus aquaculture in Nigeria could still indirectly pose a significant health burden to human consumers. Hence, the relevant regulatory agencies in Nigeria should urgently commence the monitoring of $C$. gariepinus aquaculture operations in order to eradicate the burden of multidrug resistance propagated by the aqua-cultured catfish cross-contaminations.

\section{Conclusions}

The present research provided empirical evidence which indicated that the Nigerian catfish grow-out ponds were reservoirs of pathogenic multidrug-resistant bacteria. It also revealed that the microbial burden associated with fresh catfish harvested from the grow-out pond systems was significantly ameliorated by the risk mitigation protocols practiced by human consumers in Nigeria. In spite of the significant risk mitigation, inducible AmpC beta-lactamase resistance genes was still found in the residual multidrug-resistant Enterobacter cloacae pathogen, which survived the inadequate risk mitigation protocols that accounted for $8 \%$ residual risk of illness. Because the resistance genes that originated from the contaminated catfish can be horizontally transferred to clinically relevant pathogens present in other ready-to-eat foods, the relevant regulatory agencies in Nigeria should urgently commence the monitoring of catfish aquaculture operations in order to eradicate the burden of multidrug resistance propagated by the aqua-cultured catfish crosscontaminations. 


\section{Acknowledgements}

This research received no specific grant from any funding agency in the public, commercial, or not-forprofit sectors.

\section{Conflict of Interests}

The authors declare that there are no conflicts of interest related to this article.

\section{References}

Adedeji OB, Onwenefah M (2013). The antibiotic resistant patterns of bacterial flora of cultured catfish fed with poultry hatchery waste from selected farms in Ibadan, Nigeria. Researcher 5:37-43.

Aven T (2016). Risk assessment and risk management: Review of recent advances on their foundation. European Journal of Operational Research 253:1-13.

Barker GC (2002). Risk assessment for Clostridium botulinum: a network approach. International Biodeterioration and Biodegradation 50:167-175.

Boss R, Overesch G, Baumgartner A (2016). Antimicrobial resistance of Escherichia coli, Enterococci, Pseudomonas aeruginosa, and Staphylococcus aureus from raw fish and seafood imported into Switzerland. Journal of Food Protection 79:1240-1246.

Cassin MH, Paoli GM, Lammerding AM (1998). Simulation modelling for microbial risk assessment. Journal of Food Protection 61:1560-1566.

Clinical and Laboratory Standards Institute (CLSI) (2014). Performance standards for antimicrobial susceptibility testing. Twenty-fourth informational supplement, CLSI document M100-S24, Wayne, PA, United States pp 50-57.

Codex Alimentarius Commission (1999). Principles and guidelines for the conduct of microbiological risk assessment. CAC/GL-30, Food and Agricultural Organization of the United Nations, Rome. http://www.fao.org/3/y1579e/y1579e05.htm.

Conceicao T, Faria N, Lito L, Cristino JM, Salgado JM, Duarte A (2004). Diversity of chromosomal AmpC Llactamases from Enterobacter cloacae isolates in a Portuguese hospital. FEMS Microbiology Letters 230:197-202.

Efuntoye MO, Olurin KB, Jegede GC (2012). Bacterial flora from healthy Clarias gariepinus and their antimicrobial resistance pattern. Advanced Journal of Food Science and Technology 4:121-125.

Ekundayo FO, Diyaolu DO, Fasakin EA (2014). Composition, distribution and antibiotic sensitivities of bacteria associated with cultured Clarias gariepinus (Burchell 1822). Malaysia Journal of Microbiology 10:72-79.

FDA, EPA (2017). Eating fish: what pregnant women and parents should know. www.fda.gov/fishadvice and www.epa.gov/fishadvice.

Food and Drug Administration, Center for Food Safety and Applied Nutrition, Joint Institute for Food Safety and Applied Nutrition, Risk Sciences International (FDA/CFSAN/JIFSAN/RSI) (2017). FDA-iRISK ${ }^{\bullet}$ version 4.0 Technical Document. College Park, Maryland, United States.

Imade OS, Akinnibosun FI (2018). The Nigerian catfish (Clarias gariepinus) pisciculture systems: reservoirs of multidrug-resistant bacteria. Journal of Applied Microbiology 125:1552-1568.

Jackson TC, Hardin MD, Acuff GR (1996). Heat resistance of E. coli O157:H7 in a nutrient medium and in ground beef E. coli $\mathrm{O} 157: \mathrm{H} 7$ in a nutrient medium and in ground beef. Food Protection 59:230-237.

Karch H, Meyer T (1989). Single primer pair for amplifying segments of distinct shiga-like-toxin genes by polymerase chain reaction. Journal of Clinical Microbiology 27:2751-2757.

Kirk MD, Angulo FJ, Havelaar AH, Black RE (2017). Diarrhoeal disease in children due to contaminated food. Bulletin of the World Health Organization 95:233-234.

Lane DJ (1991). 16S/23S rRNA sequencing. In: Stackebrandt E, Goodfellow M (Eds), Nucleic acid techniques in bacterial systematics. John Wiley and Sons, New York, USA pp 115-175. 
Park MS, Cho JI, Lee SH, Bahk GJ (2014). A study on dose-response models for foodborne disease pathogens. Journal of Food Hygiene and Safety 29:299-304.

Pérez-Pérez FJ, Hanson DH (2002). Detection of plasmid-mediated AmpC $\beta$-lactamase genes in clinical isolates by using multiplex PCR. Journal of Clinical Microbiology 40:2153-2162.

Pires SM, Fischer-Walker CL, Lanata CF, Devleesschauwer B, Hall AJ, Kirk MD (2015). Aetiology-specific estimates of the global and regional incidence and mortality of diarrhoeal diseases commonly transmitted through food. PLoS ONE 10:e0142927.

Public Health England (2014). Preparation of samples and dilutions, plating and sub-culture. In: Microbiology services food water and environmental microbiology standard method. FNES26 (F2), London pp 12-13.

Qadri F, Saha A, Ahmed T, Al Tarique A, Begum YA, Svennerholm AM (2007). Disease burden due to enterotoxigenic Escherichia coli in the first 2 years of life in an urban community in Bangladesh. Infection and Immunity 75:3961-3968.

Rosenberger WF, Lachin JM (2002). Randomization in Clinical Trials Theory and Practice. John Wiley and Sons pp 288.

Surendran SPK, Thampuran N (2009). PCR-based detection of enterotoxigenic isolates of B. cereus from tropical seafood. Indian Journal of Medical Research 129:316-320.

OPEN ACCESS

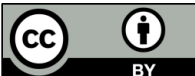

The journal offers free, immediate, and unrestricted access to peer-reviewed research and scholarly work, due SHST supports to increase the visibility, accessibility and reputation of the researchers, regardless of geography and their budgets. Users are allowed to read, download, copy, distribute, print, search, or link to the full texts of the articles, or use them for any other lawful purpose, without asking prior permission from the publisher or the author.

License - Articles published in Notulae Scientia Biologicae are Open-Access, distributed under the terms and conditions of the Creative Commons Attribution (CC BY 4.0) License.

(c) Articles by the authors; SHST, Cluj-Napoca, Romania. The journal allows the author(s) to hold the copyright/to retain publishing rights without restriction. 